\title{
How does an acidic support affect the hydrotreatment of a gasoil with high nitrogen content?
}

\author{
Minh-Tuan Nguyen', Gerhard D. Pirngruber', Florian Albrieux' ${ }^{1}$, Fabien Chainet ${ }^{1}$, Melaz \\ Tayakout-Fayolle ${ }^{2}$, Christophe Geantet ${ }^{3}$
}

${ }^{1}$ IFP-Energies nouvelles, Rond-point de l'échangeur de Solaize, BP 3, 69360 Solaize, France

2 Université de Lyon, Université Claude Bernard Lyon 1, CNRS, LAGEP UMR 5007, 43

Boulevard du 11 novembre 1918, F-69100, Villeurbanne, France

${ }^{3}$ Université de Lyon, Institut de recherches sur la catalyse et l'environnement de Lyon, IRCELYON, UMR 5256-CNRS - UCB Lyon1, 2 avenue Albert Einstein, F-69626 Villeurbanne, France

KEYWORDS: hydrodenitrogenation, hydrodesulfurization, gasoil, acidity, $\mathrm{MoS}_{2}$, silicaalumina

\begin{abstract}
Two NiMo sulfide catalysts, supported on $\mathrm{Al}_{2} \mathrm{O}_{3}$ and silica-alumina, respectively, were compared in the hydrotreating of a mixture of straight-run and coker gasoil. Experiments were conducted in a continuous fixed bed reactor, at $623-643 \mathrm{~K}$ and $5 \mathrm{MPa}$. The $\mathrm{Al}_{2} \mathrm{O}_{3}$-supported catalyst proved to be slightly more active in HDN and significantly more active in HDS than its silica-alumina analogue. The activity trend was attributed to the inhibition provoked by the strong adsorption of basic nitrogen species. Earlier work had shown that the adsorption (and thus the inhibition) was significantly stronger on an acidic support. Our data further showed that the reactivity of neutral (pyrrole benzologues) and basic nitrogen compounds was
\end{abstract}


different. The basic fraction was converted in a gradual fashion, while the large majority of neutral species was converted very quickly, except for a small fraction, which remained practically inert to hydrotreating.

\section{Introduction}

Hydrotreatment catalysts usually consist of $\mathrm{Ni}$ - or Co-promoted $\mathrm{MoS}_{2}$ nanoparticles supported on alumina. Alumina is the preferred support material because of its advantageous textural properties and its mechanical stability. In some cases, silica-alumina is used instead. Many reports in the literature suggest that the acidity of the silica-alumina has a beneficial effect on the HDN activity of NiMo-type sulfide catalysts. For example, Miranda et al. ${ }^{1}$ found a linear correlation between the content of Brønsted acid sites and the HDN rate of piperidine (amorphous silica alumina supports with different $\mathrm{Si} / \mathrm{Al}$ ratio). Prins and coworkers compared the activity of alumina and of silica-alumina supported catalysts in the HDN of o-toluidine and of methylcyclohexylamine; in both cases, the silica-alumina supported catalysts were more active ${ }^{2,3}$. Murti et al. ${ }^{4}$ observed the same result in the hydrotreatment of coal derivate liquid. Introducing acidity into an alumina support by grafting of silica also improved the HDN activity in the hydroconversion of Safaniya vacuum residue ${ }^{5}$. Fluorination of the support also has a positive effect on the HDN activity ${ }^{6}$. The positive impact of support acidity on HDN activity has also been observed with industrial catalysts. Minderhoud and van Veen ${ }^{7}$ reported that silica-alumina supported catalysts were more active in the HDN of Vacuum Gas Oil than alumina-supported catalysts.

This beneficial effect of support acidity on HDN activity was explained by different theories: 
(i) Kozai and co-workers ${ }^{8}$ proposed that acid sites of amorphous silica-alumina (ASA) are directly involved in the breaking of the $\mathrm{C}-\mathrm{N}$ bond in methyl-cyclohexylamine to form methyl-cyclohexene.

(ii) The interaction of $\mathrm{MoS}_{2}$ with an acidic support modifies the electronic properties of sulfide phase ${ }^{6,9-11}$. It induces an electron deficiency in the sulfide phase, via a transfer of electrons to the support. This modification is expected to influence the reactivity and the adsorption properties of the sulfide slabs.

(iii) Prins and co-workers ${ }^{2,3,12}$ reported that the adsorption constants of o-methyl-aniline, methylcyclohexylamine and cylohexene over NiMo/ASA were systematically higher than over NiMo/ $\mathrm{Al}_{2} \mathrm{O}_{3}$. The stronger adsorption contributes to a higher activity of the ASAsupported catalysts for certain reactions in the HDN network.

(iv) Compared to an alumina support, silica-alumina modifies the dispersion (i.e. slab size and stacking) of the sulfide nanoparticles. Yet, due to the large diversity of silica-alumina materials, literature provides conflicting evidence: some report that the incorporation of silica into the support deteriorates dispersion, ${ }^{13}$ whereas in other studies the impact on slab length was negligible ${ }^{14,15}$.

(v) Hensen et al. ${ }^{16}$ showed that the acidity of the support leads to a higher sulfur tolerance, i.e. the active sites are less sensitive to inhibition by $\mathrm{H}_{2} \mathrm{~S}$. This means that silicaalumina supports should be especially attractive for high pressure applications, in a sulfur rich environment. This is in line with the observation that silica-alumina is a good support for VGO hydrotreating.

We recently reported a detailed comparison of the behavior of alumina and silicaalumina supported NiMo catalysts in the HDN of two model molecules, i.e. quinoline ${ }^{17}$ and indole ${ }^{18}$. Comprehensive kinetic modeling allowed us to distinguish the influence of support on adsorption and intrinsic rate constants. The studies showed that the support acidity indeed 
enhanced the intrinsic rate constants of the rate-limiting hydrogenation steps in the HDN network of quinoline, presumably due to the modification of the electronic properties of the sulfide slabs. At the same time, the adsorption of reactants and intermediates on the active sites was also stronger, which led to a strong self-inhibition of quinoline, i.e. in fine a negative effect on catalytic activity. The silica-alumina support also modified the concentration of promoted NiMoS sites at the edges of the $\mathrm{MoS}_{2}$ slabs. In our specific case, it decreased, but this conclusion should not be generalized since the concentration of promoted sites strongly depends on the preparation method. Overall, the combination of the three above-mentioned factors (adsorption, intrinsic rate constant and concentration of promoted sites) led to a decrease of the HDN activity (vs. an alumina supported catalyst) in the HDN of quinoline and a similar activity of both catalysts in the case of indole. Yet, it is not straightforward to extrapolate the behavior with model molecule to real feeds, because they are very complex mixtures for which mutual inhibition effects between HDS and HDN are hard to predict. In the present study, which is based on Chapter 5 of the PhD thesis of M. T. Nguyen ${ }^{19}$, we therefore compared the performance of the alumina and silica-alumina supported NiMo catalysts in the hydrotreatment of a gasoil mixture. Since our focus was on evaluating HDN, we chose for this purpose a mixture of straight run gasoil and coker gasoil leading to a feed with high nitrogen content and a wide variety of $\mathrm{N}$ compounds.

\section{Materials and methods}

\subsection{Catalysts}

The NiMo(P)/ $/ \mathrm{Al}_{2} \mathrm{O}_{3}$ and $\mathrm{NiMo}(\mathrm{P}) / \mathrm{ASA}$ (Amorphous Silica-Alumina) catalysts were identical to those described and characterized in our previous works ${ }^{17,18}$. Their main characteristics are compiled in Table 1. The metal content of the two catalysts were selected so as to obtain the same volumetric activity in the hydrogenation of toluene ${ }^{17}$. The reasoning behind this 
approach was that HDN reactions necessarily imply the hydrogenation of aromatic rings. By choosing two catalysts with the "same" hydrogenation activity for benzene rings, differences in HDN can be attributed to specificities in the adsorption and activation of nitrogen containing rings.

The acidity of the ASA catalyst was characterized via its activity in the isomerization of cyclohexane: it was at least four times more active than its $\mathrm{Al}_{2} \mathrm{O}_{3}$ counterpart ${ }^{17}$. The detailed characterization of the acidity of the ASA support was already carried out in previous work ${ }^{20}$. Our ASA support is similar to the Si30Al70 sample in the before-mentioned reference.

Table 1: Properties of the $\mathrm{NiMo}(\mathrm{P}) / \mathrm{Al}_{2} \mathrm{O}_{3}$ and $\mathrm{NiMo}(\mathrm{P}) / \mathrm{ASA}$ catalysts ${ }^{17}$

\begin{tabular}{lcc}
\hline & $\mathrm{NiMo}(\mathrm{P}) / \mathrm{Al}_{2} \mathrm{O}_{3}$ & $\mathrm{NiMo}(\mathrm{P}) / \mathrm{ASA}$ \\
\hline$\%$ wt $\mathrm{MoO}_{3}$ & $18.6 \%$ & $14.0 \%$ \\
$\% \mathrm{wt} \mathrm{NiO}$ & $3.84 \%$ & $2.97 \%$ \\
$\%$ wt $\mathrm{P}_{2} \mathrm{O}_{5}$ & $4.93 \%$ & $3.84 \%$ \\
Compacted bulk density, $\mathrm{g} / \mathrm{cm}^{3}$ & 0.77 & 0.93 \\
Average $\mathrm{MoS}_{2}$ slab length $/ \mathrm{nm}$ & 6.1 & 6.6 \\
NiMoS site density, $\left(\mathrm{mmol} \mathrm{NiMoS} / \mathrm{cm}^{3}\right)$ & 0.424 & 0.318 \\
\hline
\end{tabular}

\subsection{Gasoil feed mixture}

The gasoil feed was a mixture of $50 \mathrm{wt} \%$ of straight run gasoil and $50 \mathrm{wt} \%$ of coker gasoil. Properties of individual gasoils and gasoil mixture are given in Table 2. A more detailed analysis of the nitrogen and sulfur species at a molecular level was performed by GCxGC either with a sulfur or nitrogen specific detector (SCD or NCD), respectively (see appendix for details). 
Table 2: Properties of straight run gasoil, coker gasoil and their mixture

\begin{tabular}{lccc}
\hline & Straight Run GO & Coker GO & Gasoil feed blend \\
\hline Total nitrogen (wppm) & $96 \pm 5$ & $1320 \pm 99$ & $703 \pm 53$ \\
Basic nitrogen (wppm) & 47.9 & 569 & $290 \pm 23$ \\
Total sulfur (wt \%) & 0.44 & 2.38 & 1.44 \\
Density at $15^{\circ} \mathrm{C}(\mathrm{g} / \mathrm{ml})$ & 0.849 & 0.882 & 0.865 \\
Boiling point range $(5-95 \%)\left({ }^{\circ} \mathrm{C}\right)^{\mathrm{a}}$ & $187-390$ & $193-402$ & $190-397$ \\
Kinematic viscosity at $20^{\circ} \mathrm{C}\left(\mathrm{mm}^{2} / \mathrm{s}\right)$ & 6.2 & 6.1 & 6.2 \\
$\quad$ Kinematic viscosity at $40^{\circ} \mathrm{C}\left(\mathrm{mm}^{2} / \mathrm{s}\right)$ & 3.8 & 3.7 & 3.8 \\
\hline
\end{tabular}

\subsection{Catalytic tests in fixed-bed continuous reactor and analysis of effluents}

Catalytic tests were performed in a three phase fixed-bed reactor in up-flow mode. A detailed description of the setup is provided in the supporting information.

$1 \mathrm{~cm}^{3}$ of catalyst was loaded into the reactor in the form of ground particles (sieve fraction 80 and $125 \mu \mathrm{m}$ ). The hydrotreatment reactions were performed at a pressure of $5 \mathrm{MPa}$. A value of temperature was fixed during each run, i.e. 350,360 or $370^{\circ} \mathrm{C}$. Conversion was varied by adjusting the LHSV in the range of 2-6 $\mathrm{h}^{-1}$ (starting at a high LHSV and going to low a LHSV). The inlet $\mathrm{H}_{2} /$ hydrocarbon ratio was fixed at $400 \mathrm{NL} / \mathrm{L}$. Deactivation was evaluated by returning to the initial LHSV at each temperature. In order to quantify catalytic activity, apparent rate constants were calculated from $r=k \cdot C^{n}$ rate law (see supporting information).

The liquid reactor effluent was analyzed by UV Fluorescence to determine total sulfur content and by chemiluminescence (ANTEK 9000NS) to determine the total nitrogen content. The basic nitrogen content was measured by potentiometric titration (ASTM D2896). The global evolution of the different molecular families was followed by mass spectroscopy. The MS method, which is derived from ASTM D2425, is described in detail in ref. ${ }^{21}$. It quantifies twelve groups in $w t \%$ according to their stoichiometric formula: paraffins $\left(\mathrm{C}_{\mathrm{n}} \mathrm{H}_{2 \mathrm{n}+2}\right)$, non- 
condensed naphthenes $\left(\mathrm{C}_{n} \mathrm{H}_{2 n}\right)$, condensed two and three ring-naphthenes $\left(\mathrm{C}_{n} \mathrm{H}_{2 n-2}\right.$ and $\mathrm{C}_{n} \mathrm{H}_{2 n}$ 4), seven aromatic families (from $\mathrm{C}_{\mathrm{n}} \mathrm{H}_{2 \mathrm{n}-6}$ to $\mathrm{C}_{\mathrm{n}} \mathrm{H}_{2 \mathrm{n}-18}$ ), which were regrouped in mono-, diand triaromatics in our analysis, as well as benzothiophene and dibenzothiophenes. The contribution of each group-type is determined by the sum of the molecular peaks $\mathrm{M}^{+}$and/or fragment peaks $(\mathrm{M}-\mathrm{H})^{+}$, weighed by the average response coefficient and corrected for the contribution of the other group-types.

At the end of experiment, the catalyst was unloaded and sieved by a molecular sieve in order to remove $\mathrm{SiC}$ particles contaminants (particle size smaller than $50 \mu \mathrm{m}$ ). The catalysts were then washed with Soxhlet apparatus using heptane as a solvent at $85^{\circ} \mathrm{C}$ during 24 hours. Finally, the catalysts were then dried under vacuum $(10 \mathrm{mPa})$ at $100^{\circ} \mathrm{C}$ for 24 hours. The content of deposited carbon and nitrogen on the used catalysts was measured by CHNS analysis.

In order to make sure that the catalytic tests measured actual chemical kinetics and not mass transfer rates, we estimated the characteristic times of external and internal mass transfer (see supporting information). The characteristic time of external mass transfer was in the order of $0.03 \mathrm{~s}$, the one of internal transfer was less than $1 \mathrm{~s}$, i.e. both were negligibly small compared to the characteristic time of chemical kinetics $(>1 \mathrm{~h})$.

\section{Results}

\subsection{Analysis of the gasoil feed mixture}

Our study uses a mixture of straight run gasoil (SRGO) and coker gasoil (CGO) (50/50 wt \%). The straight run gasoil has low nitrogen content ( $\sim 100 \mathrm{ppm})$. At the sulfur levels of Ultra Low Sulfur Diesel (ULSD), HDN of a SRGO is complete and the HDN activity of catalysts is considered as not to be critical for such "easy" feeds. We, therefore, chose to mix the SRGO 
with a more difficult feed, coming from coking of a vacuum residue. This CGO has a very high nitrogen content of $1300 \mathrm{ppm}$, and in contrast to Light Cycle Oils (LCO) coming from FCC processes, a large fraction of the organic nitrogen belongs to basic nitrogen species (43\%), which are known to be the strongest inhibitors ${ }^{22}$.

Analysis of sulfur compounds in gasoil mixture by GCxGC-SCD provided the distribution of refractory sulfur compounds in the feed. The gasoil mixture contained a large amount of alkylated dibenzothiophenes (DBT) compounds, especially $\mathrm{C}_{3}{ }^{+}$-DBT (10.6\%). These compounds are well known to be refractory compounds towards the HDS reaction ${ }^{23-28}$. Figure 1 shows the distribution of families of sulfur compounds in the feed.

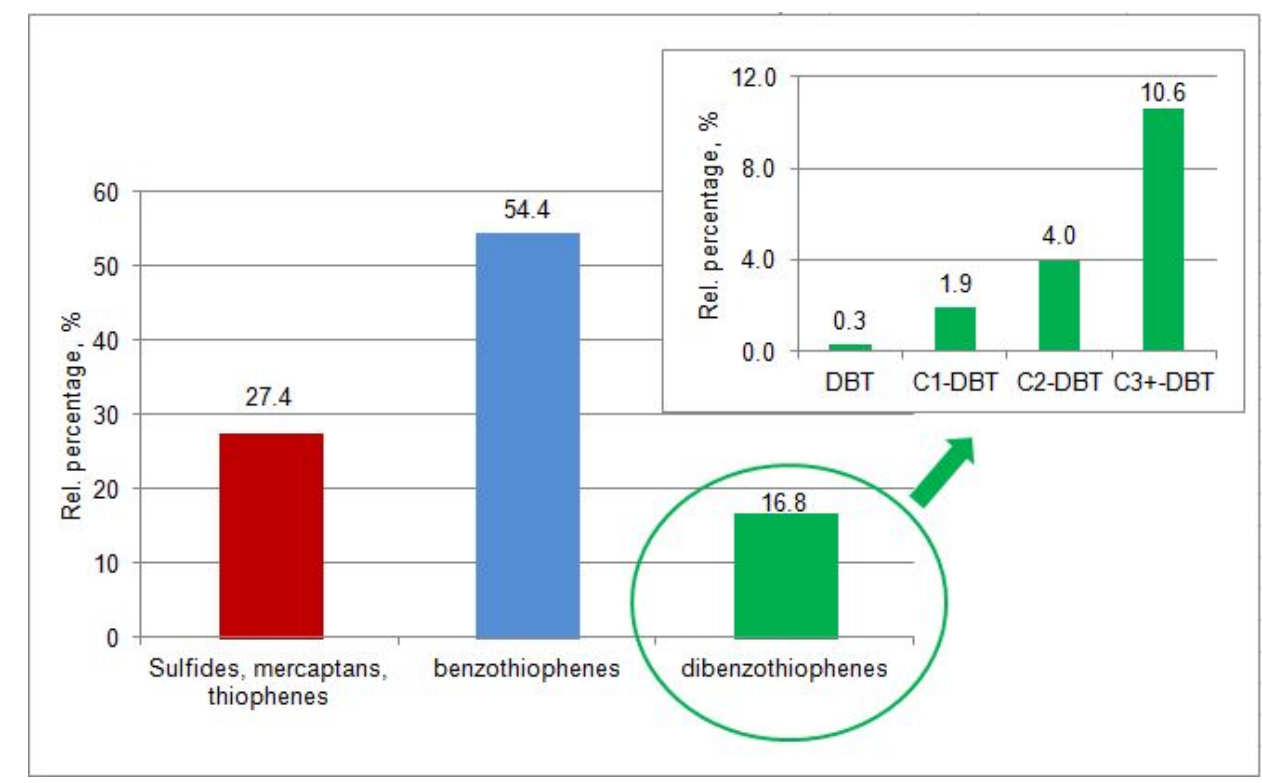

Figure 1: Family analysis of sulfur compounds in the gasoil mixture by comprehensive gas chromatography coupled with sulfur Chemiluminescence detector.

The distribution of nitrogen organic compounds in the gasoil mixture was obtained from GCxGC-NCD. The identification of each family was carried out thanks to a standard mixture and GCxGC/MS characterization ${ }^{29,30}$. The GCxGC-NCD chromatogram is given in Figure 2. 


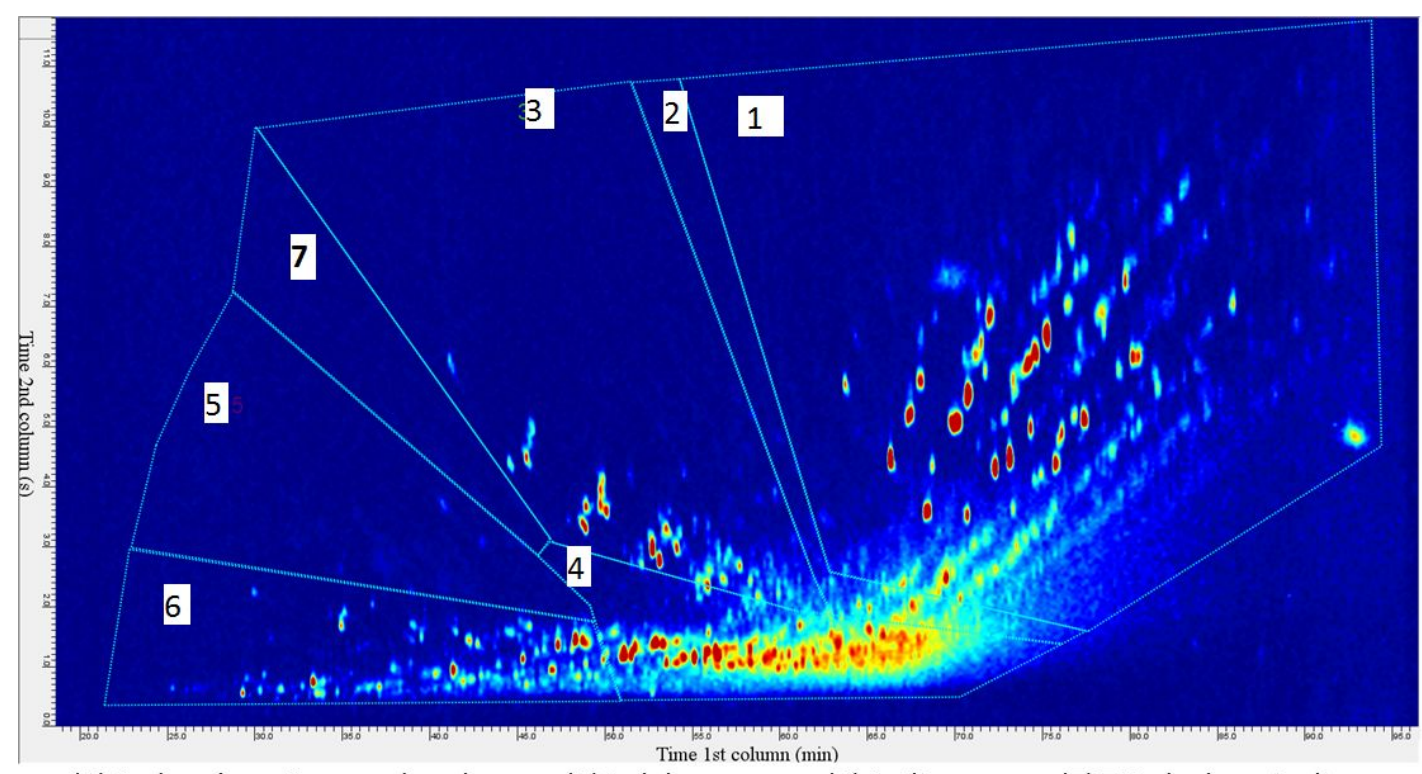

(1) Carbazoles + Benzocarbasoles

(3) Indoles

(5) Anilines

(7) Tetrahydroquinolines

(2) Acridines + Tetrahydrocarbazoles

(4) Quinolines

(6) Pyridines

Figure 2: Semi-quantitative analysis by comprehensive gas chromatography coupled with nitrogen chemiluminescence detector of nitrogen compounds in the gasoil mixture

In Figure 2, we can see the speciation in several families of N-compounds in the gasoil feed mixture. Semi-quantification was carried out by calculating the ratio of peak volume of each family as compared to total peak volume. The relative percentage of each family of Ncompounds is given in Figure 3. An overlap between several families such as alkyl-pyridine and alkyl-quinoline, alkyl-acridine and alkyl-carbazole did not allow a precise quantification. Moreover, alkyl-carbazole and alkyl-benzocarbazole were eluted in the same zone in the chromatogram. 


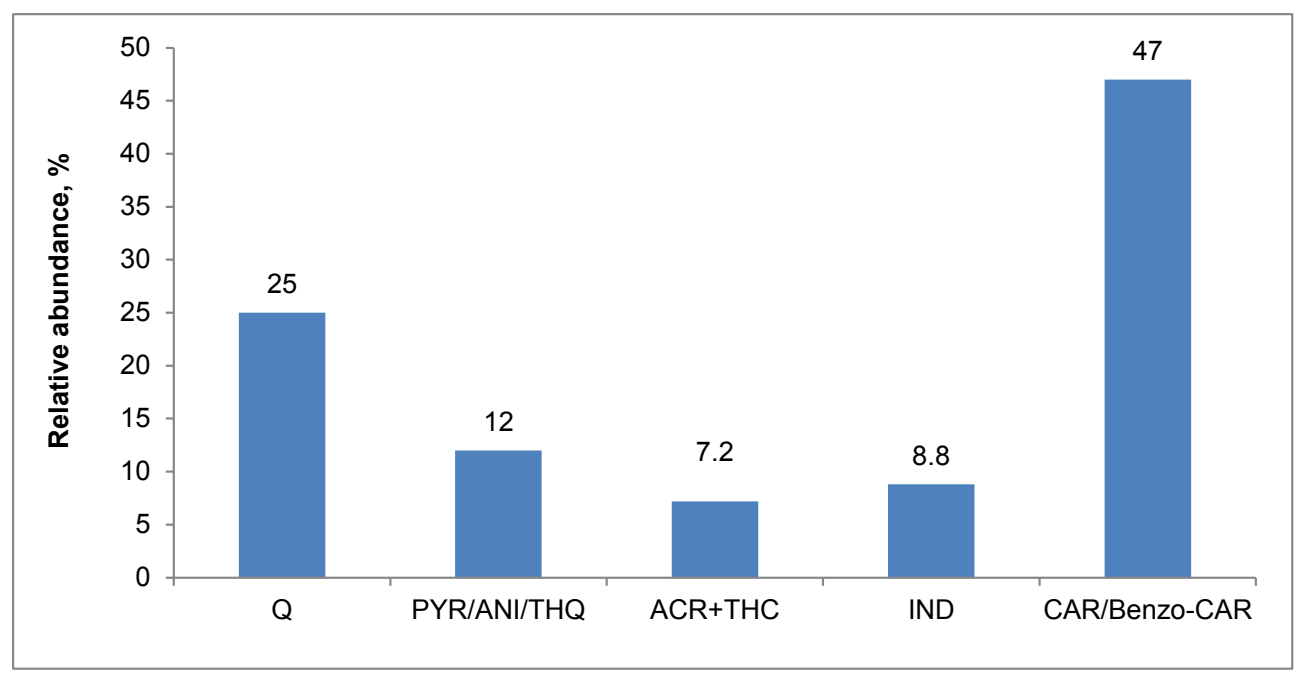

Figure 3: Distribution of N-compound families from GCxGC-NCD analysis

(In this figure: Q: quinoline-; PYR: pyridine-, ANI: aniline-, THQ: tetrahydroquinoline-, ACR: acridine-, THC: tetrahydrocarbazole-, IND: indole- and CAR: carbazole- type compounds)

Figure 3 indicates that the gasoil mixture contained mainly carbazole and benzocarbazole type compounds, which are well known to be highly refractory towards hydrotreating reactions. There was also a significant amount of (basic) quinoline type compounds (25\%). The relative percentage of all basic N-compounds families (quinoline-, PYR/ANI/THQ-, and acridine-type compounds) represented $44 \%$ of the total N-compounds. This result is very close to $41 \%$ of basic nitrogen obtained by potentiometric titration (Table 2 ).

\subsection{Catalytic conversion of the SRGO + CGO mixture}

\subsubsection{Global evolution of the GO composition during hydrotreating}

The MS analysis allows us to follow globally the evolution of different molecular families during hydrotreating. We show the results obtained with the ASA-supported catalyst, the trends for the $\mathrm{Al}_{2} \mathrm{O}_{3}$-supported sulfide catalyst were similar. 


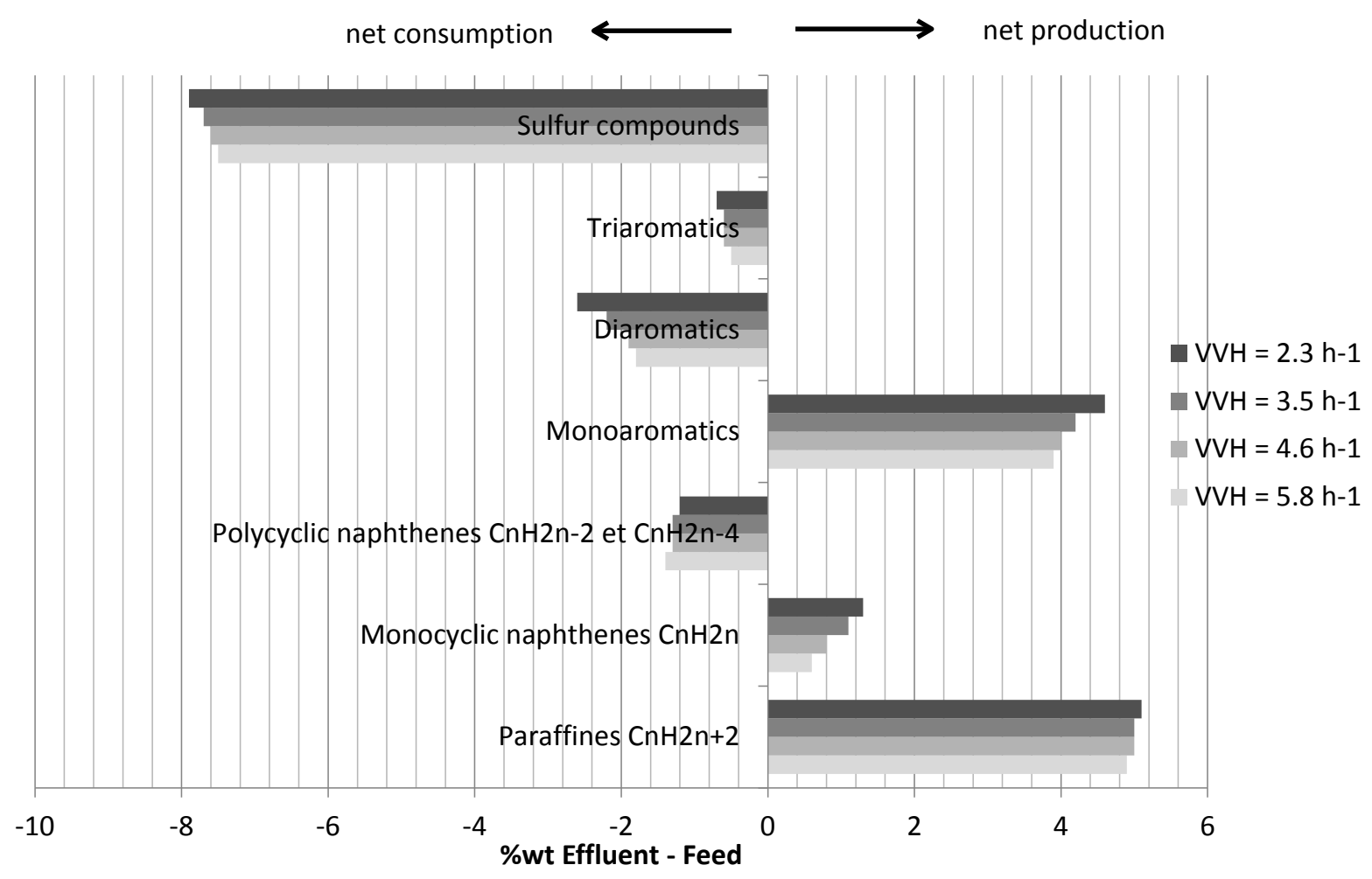

Figure 4: Change in composition between feed and effluent: decrease/increase in the mass percentage of paraffines, non-condensed naphthenes, condensed naphthenes, monoaromatics, diaromatics, triaromatics and sulfur compounds upon hydrotreatment over the ASA-supported catalyst.

The shifts in composition of the gasoil (Figure 4) were mainly due to the conversion of sulfur compounds and of aromatics. The increase in the concentration of paraffins could be attributed to the desulfurization of sulfides, mercaptanes and thiophenes in the feed. Monoaromatics were formed by direct desulfurization of benzo- and dibenzothiophenes as well as by hydrogenation of diaromatics. At high residence time, the monoaromatics were further converted into monocyclic naphthenes. The decrease of polycyclic naphthenes at short residence time was tentatively attributed to ring opening reactions. With increasing residence time the concentration of these compounds slightly increased again. This was ascribed to the slow hydrogenation of bi-phenyl compounds, which had been formed by direct desulfurization of dibenzothiophenes. The remaining sulfur compounds were benzo- and dibenzothiophenes. 


\subsubsection{HDS and HDN conversion}

Figure 5 shows the HDS and HDN conversion as a function of residence time for the two catalysts. The HDS conversions were in the range of 90 to $98 \%$. This corresponds to a residual sulfur concentration in the range of 200 to $700 \mathrm{ppmw}$, i.e. not yet at ultra-low sulfur diesel levels. This is the conversion range where mainly the most refractive sulfur compounds, i.e. the dibenzothiophenes, which represent $16 \%$ of the sulfur compounds in the feed (Figure 2), are converted.

The alumina-supported catalyst was significantly more active in HDS. This result is in line with Couman's work ${ }^{15}$; he already found that the silica-alumina supported NiMo catalysts were less active in HDS of DBT than alumina-supported ones. The alumina-supported catalyst also showed a higher HDN activity, but the difference between the two catalysts was less pronounced than in HDS. The ratio of the apparent rate constants at $350^{\circ} \mathrm{C}\left(\mathrm{Al}_{2} \mathrm{O}_{3} \mathrm{vs}\right.$. ASA) was equal to 1.1 , i.e. close to ratio obtained for quinoline HDN, which was equal to 1.2 17. The difference of the HDS rate constants was significantly higher (factor of 1.7 in favor of $\left.\mathrm{Al}_{2} \mathrm{O}_{3}\right)$
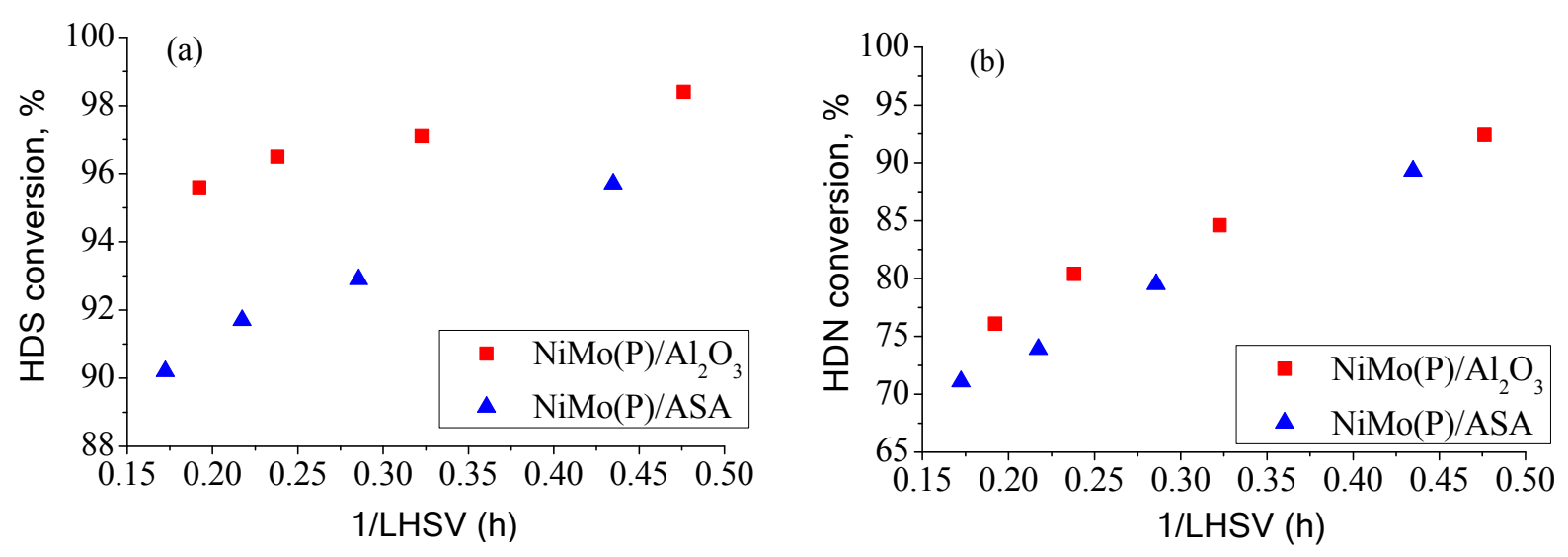

Figure 5: HDS (a) and HDN (b) conversion activity of the two catalysts at $360^{\circ} \mathrm{C}$ 


\subsubsection{Deactivation}

As mentioned in the experimental section, the deactivation of the catalysts was evaluated by returning to the initial reaction conditions at the end of the run at each temperature. A comparison of the rate constant at the end of the run with the rate constant at the beginning of the run allowed evaluating the extent of deactivation. The loss of HDS activity was between 13 and $15 \%$ for both catalysts. The deactivation of HDN was less pronounced for the alumina supported catalyst (5\%) than for the silica-supported catalyst (10\%). The stronger deactivation of the silica-alumina supported catalyst was already observed in the HDN of quinoline and indole. The carbon and nitrogen contents in used $\mathrm{NiMo}(\mathrm{P}) / \mathrm{Al}_{2} \mathrm{O}_{3}$ were $5.0+/-0.02$ and 0.37 +/- $0.06 \mathrm{wt} \%$, respectively. The corresponding values for used NiMo(P)/ASA were $5.3+/-$ 0.04 and $0.47+/-0.04 \mathrm{wt} \%$, respectively. The carbon contents were close, but the nitrogen content was significantly higher on silica-alumina, due to the stronger adsorption of basic nitrogen species on this support. The stronger irreversible adsorption of nitrogen probably explains the stronger deactivation.

\subsubsection{Basic and neutral nitrogen species}

The behavior of neutral pyrrole benzologues and basic nitrogen species in hydrotreatment is quite different. It is, therefore, interesting to follow the evolution of the two families as a function of residence time. Figure 6 shows the concentration profiles for the NiMo(P)/ASA catalyst. The results for the alumina-supported catalyst were qualitatively similar. We can see that the concentration of neutral nitrogen species dropped rapidly and then remained constant. The decrease of the basic nitrogen concentration was a lot more gradual. 


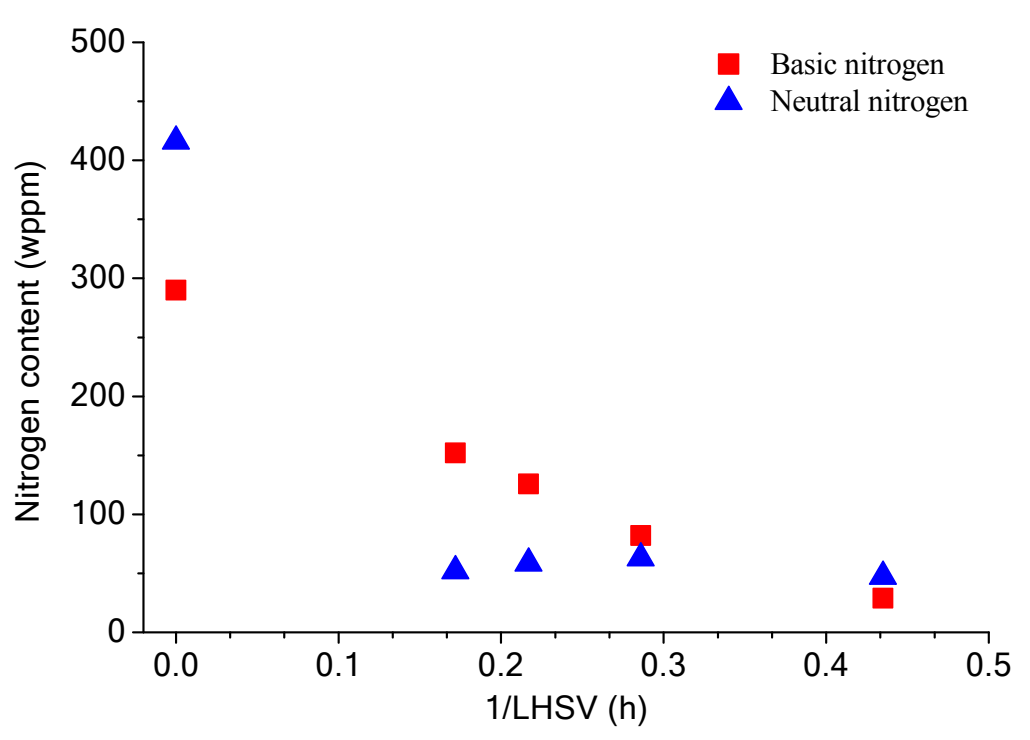

Figure 6: Evolution of neutral and basic nitrogen content as a function of residence time, over $\mathrm{NiMo}(\mathrm{P}) / \mathrm{ASA}$ catalyst at $360^{\circ} \mathrm{C}$.

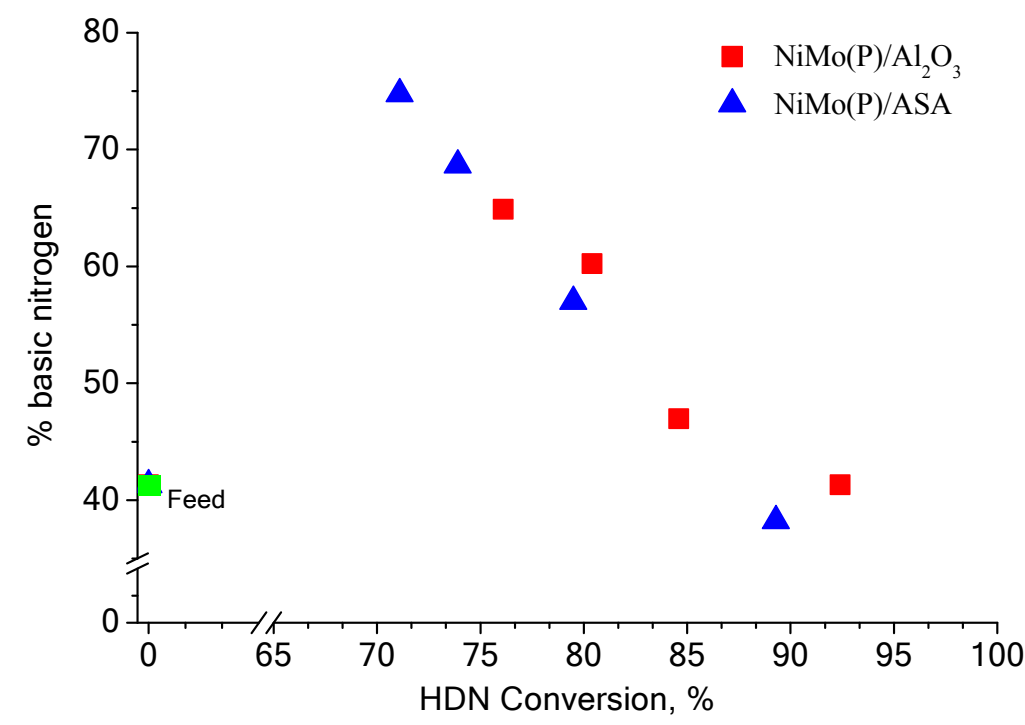

Figure 7: Relative percentage of basic nitrogen content in the feed and effluents at $360^{\circ} \mathrm{C}$ as function of HDN conversion

Figure 7 shows how the fraction of basic nitrogen species evolves as a function of HDN conversion for the two catalysts. At high HDN conversion, the fraction of basic nitrogen species was slightly lower on the ASA-supported catalyst, which suggests that the acidic support has a small preference for the conversion of the basic species. In other words, the HDN of neutral species is more inhibited by the competitive adsorption of basic species on 
the more acidic catalyst; hence the relative abundance of neutral nitrogen was slightly higher on the ASA catalyst.

\section{Discussion}

In the hydrotreating of nitrogen rich gasoil feed with a high concentration of basic nitrogen species, the HDN activity of a silica-alumina supported catalyst was lower than that of an alumina supported catalyst. This matches the behavior observed in the HDN of quinoline ${ }^{17}$. We assume that, as in the case in quinoline, the strong adsorption of the basic nitrogen species leads to auto-inhibition and, hence, reduces the catalytic activity of ASA vs. $\mathrm{Al}_{2} \mathrm{O}_{3}$. For the sake of clarity we note that when we speak about adsorption, we refer to adsorption on the active sites and not to adsorption on the support; the adsorption constants in our earlier work were obtained from kinetic modelling, i.e. adsorption on sites, which do not participate in catalysis, was not accounted for.

The majority of the neutral species was converted very quickly (Figure 6). The hydrogenation of the aromatic rings in a neutral nitrogen species creates a basic reaction intermediate. One could, therefore, imagine that the neutral nitrogen species are not really HDN-converted, but simply transferred to the basic nitrogen pool. However, model molecule studies with carbazole derivatives or indole showed that the basic intermediate is rarely detected because it undergoes C-N bond scission very quickly ${ }^{18,31,32}$. We can, therefore, assume that this rule also applies to gasoil feeds.

While the majority of neutral nitrogen species was very reactive and rapidly HDN-converted, there was a certain fraction, which was extremely refractory (Figure 6). Its concentration hardly decreased even at the highest HDN conversions reached in this study. Analysis of the effluent by mass spectrometry showed that the refractory pyrrole benzologues were mainly 
carbazole and tetrahydrocarbazole-species, in agreement with the literature ${ }^{33-35}$. A more detailed discussion of the molecular level analysis of the effluents is, however, beyond the scope of the present contribution and will be presented in a separate paper.

Another observation that merits a brief discussion is that the gap in the HDS activity of the two catalysts is much bigger than the difference in HDN activity. In our model molecule study on quinoline, we had identified that the support acidity had two antagonistic effects: it enhanced the intrinsic reaction rate for hydrogenation reactions, but it also led to autoinhibition because of a very strong adsorption of the intermediates. The enhancement of the intrinsic hydrogenation activity moderated the auto-inhibition effect. At the moderate HDS levels that we are dealing with in this study, we can presume that the direct desulfurization pathway (which does not involve hydrogenation of the aromatic rings) contributes to a large share of the overall activity. Hence, HDS does not benefit as much as HDN from the enhanced intrinsic hydrogenation activity of the acidic support, but it is negatively impacted by the stronger inhibition (due to the stronger competitive adsorption of basic nitrogen species). We believe that this phenomenon can explain the mediocre HDS activity of the ASA-supported catalyst. More extensive coking on the ASA support might also play a role, but the CHNS of the used catalysts indicates that the carbon content of both catalysts is not very different. Thus, enhanced coke formation is probably not the major cause of the lower HDS activity.

The discussions above are based on the data obtained with a SRGO + CGO feed. We verified whether the trends also apply to other types of gasoil, in particular to LCO feeds, which have a very low fraction of basic nitrogen species. The results of hydrotreating tests with a SRGO + LCO feed are described in the supporting information. Globally the same trends were observed: the alumina-supported catalyst was more active in HDS and also in HDN. Recent papers showed that indole and quinoline were both strong inhibitors of HDS of an SRGO; the 
inhibiting effect of the quinoline was only marginally stronger than that of indole ${ }^{36,37}$. We, therefore, presume that our hypotheses expressed above also apply to LCO feeds: the bad performance of the ASA support is mainly attributable to the stronger inhibition by nitrogen species, even if the large majority of them are pyrrole benzologues.

\section{Conclusions}

An ASA-supported NiMo catalyst and an alumina-supported NiMo catalyst, both having the same the activity in toluene hydrogenation, were compared in the hydrotreating of SRGO + CGO and of SRGO + LCO. In both cases, the ASA-supported was less active in HDN and HDS than its $\mathrm{Al}_{2} \mathrm{O}_{3}$-supported analogue. We presume that the activity difference can be mainly attributed to inhibition by basic, but also by neutral nitrogen species, which are more strongly adsorbed on the ASA-catalyst ${ }^{17,18}$.

Concerning the behavior of neutral (pyrrole type) and basic nitrogen species in the CGOcontaining feed, our study suggests that deep HDN levels are achieved by pushing the conversion of the residual basic nitrogen species. Neutral nitrogen species show two extreme behaviors: either they are converted very quickly or they remain inert up to very high conversion levels. The refractory pyrrole benzologues are alkylated carbazole and tetrahydrobenzocarbazole species, as will be demonstrated in a separate paper.

Supporting information: GC analysis methods, evaluation of mass transfer in the catalytic tests, results of catalytic tests with an LCO + SRGO feed. 


\section{References}

(1) Rajagopal, S.; Grimm, T. L.; Collins, D. J.; Miranda, R. Denitrogenation of piperidine on alumina, silica, and silica-aluminas: The effect of surface acidity. J. Catal. 1992, 137, $453-461$.

(2) Qu, L.; Flechsenhar, M.; Prins, R. Kinetics of the hydrodenitrogenation of o-toluidine over fluorinated $\mathrm{NiMoS} / \mathrm{Al}_{2} \mathrm{O}_{3}$ and NiMoS/ASA catalysts. J. Catal. 2003, 217, 284-291.

(3) Qu, L.; Prins, R. The Effects of in Situ Fluorination and Support on the Hydrodenitrogenation of Methylcyclohexylamine. J. Catal. 2002, 210, 183-191.

(4) Murti, S. D. S.; Choi, K.-H.; Sakanishi, K.; Okuma, O.; Korai, Y.; Mochida, I. Analysis and removal of heteroatom containing species in coal liquid distillate over NiMo catalysts. Fuel 2005, 84, 135-142.

(5) Marques, J.; Guillaume, D.; Merdrignac, I.; Espinat, D.; Brunet, S. Effect of catalysts acidity on residues hydrotreatment. Appl. Catal. B Environ. 2011, 101, 727-737.

(6) Han, W.; Nie, H.; Long, X.; Li, M.; Yang, Q.; Li, D. Preparation of F-doped $\mathrm{MoS}_{2} / \mathrm{Al}_{2} \mathrm{O}_{3}$ catalysts as a way to understand the electronic effects of the support Brønsted acidity on HDN activity. J. Catal. 2016, 339, 135-142.

(7) Minderhoud, J. K.; van Veen, J. A. R. First-stage hydrocracking: process and catalytic aspects. Fuel Process. Technol. 1993, 35, 87-110.

(8) Kozai, S.; Kabashima, H.; Hattori, H. Participation of acidic sites on catalyst in hydrodenitrogenation of quinoline. Fuel 2000, 79, 305-310.

(9) Breysse, M.; Cattenot, M.; Kougionas, V.; Lavalley, J-C.; Mauge, F.; Portefaix, J-L.; Zotin, J -L. Hydrogenation Properties of Ruthenium Sulfide Clusters in Acidic Zeolites. J. Catal. 1997, 168, 143-153.

(10) Rocha, A. S.; Faro, A. C.; Oliviero, L.; Antoine Lélias, M.; Travert, A.; van Gestel, J.; Maugé. F. Effect of the electronic properties of Mo sulfide phase on the hydrotreating 
activity of catalysts supported on $\mathrm{Al}_{2} \mathrm{O}_{3}, \mathrm{Nb}_{2} \mathrm{O}_{5}$ and $\mathrm{Nb}_{2} \mathrm{O}_{5} / \mathrm{Al}_{2} \mathrm{O}_{3}$. Catal. Lett. 2006, 111, $27-34$.

(11) Hédoire, C-E.; Louis, C.; Davidson, A.; Breysse, M.; Maugé, F.; Vrinat, M. Support effect in hydrotreating catalysts: hydrogenation properties of molybdenum sulfide supported on $\beta$-zeolites of various acidities. J. Catal. 2003, 220, 433-441.

(12) Qu, L.; Prins, R. Hydrogenation of Cyclohexene over in Situ Fluorinated NiMoS Catalysts Supported on Alumina and Silica-Alumina. J. Catal. 2002, 207, 286-295.

(13) Leyva, C.; Rana, M. S.; Ancheyta, J. Surface characterization of $\mathrm{Al}_{2} \mathrm{O}_{3}-\mathrm{SiO}_{2}$ supported NiMo catalysts: An effect of support composition. Catal. Today 2008, 130, 345-353.

(14) Ferraz, S. G. A.; Zotin, F. M. Z.; Araujo, L. R. R.; Zotin, J. L. Influence of support acidity of NiMoS catalysts in the activity for hydrogenation and hydrocracking of tetralin. Appl. Catal. Gen. 2010, 384, 51-57.

(15) Coumans, A. E.; Poduval, D. G.; van Veen, J. A. R.; Hensen, E. J. M. The nature of the sulfur tolerance of amorphous silica-alumina supported $\mathrm{NiMo}(\mathrm{W})$ sulfide and $\mathrm{Pt}$ hydrogenation catalysts. Appl. Catal. Gen. 2012, 411-412, 51-59.

(16) Hensen, E. J. M.; de Beer, V. H. J.; van Veen, J. A. R.; van Santen, R. A. On the sulfur tolerance of supported $\mathrm{Ni}(\mathrm{Co}) \mathrm{Mo}$ sulfide hydrotreating catalysts. J. Catal. 2003, 215, $353-357$.

(17) Nguyen, M.-T.; Tayakout-Fayolle, M.; Chainet, F.; Pirngruber, G. D.; Geantet, C. Use of kinetic modeling for investigating support acidity effects of NiMo sulfide catalysts on quinoline hydrodenitrogenation. Appl. Catal. Gen. 2017, 530, 132-144.

(18) Nguyen, M.-T.; Pirngruber, G. D.; Chainet, F.; Geantet, C.; Tayakout, M. Indole Hydrodenitrogenation over Alumina and Silica-Alumina-Supported Sulfide Catalysts Comparison with Quinoline. 2017, 56 (39), 11088-11099. 
(19) Nguyen, M. T. Chapter 5, PhD Thesis: Support acidity effects of sulfide catalysts in hydrodenitrogenation: From model molecules to gasoil conversions. (Université Claude Bernard Lyon 1, 2016, pp 158-214.

(20) Crépeau, G.; Montouillout, V.; Vimont, A.; Mariey, L.; Cseri, T.; Maugé, F. Nature, Structure and Strength of the Acidic Sites of Amorphous Silica Alumina: An IR and NMR Study. J. Phys. Chem. B, 2006, 110, 15172-15185.

(21) Fafet, A.; Bonnard, J.; Prigent, F. New Developments in Mass Spectrometry for GroupType Analysis of Petroleum Cuts (First Part). Oil Gas Sci. Technol. 1999, 54, 439-452.

(22) Katti, S. S.; Gates, B. C.; Petrakis, L. Catalytic hydroprocessing of SRC-II heavy distillate fractions. 6. Hydroprocessing of the bases and neutral resins. Ind. Eng. Chem. Process Des. Dev. 1986, 25, 618-626.

(23) Perot, G.; Michaud, P.; Lemberton, J. L. Deep hydrodesulfurization of gasoils/mechanism of alkyldibenzothiophene transformation on bifunctional catalysts. Abstr. Pap. Am. Chem. Soc. 1998, 216, 881.

(24) Rabarihoela-Rakotovao, V.; Brunet, S.; Perot, G.; Diehl, F. Effect of $\mathrm{H}_{2} \mathrm{~S}$ partial pressure on the HDS of dibenzothiophene and 4,6-dimethyldibenzothiophene over sulfided $\mathrm{NiMoP} / \mathrm{Al}_{2} \mathrm{O}_{3}$ and $\mathrm{CoMoP} / \mathrm{Al}_{2} \mathrm{O}_{3}$ catalysts. Appl. Catal. Gen. 2006, 306, 34-44.

(25) Díaz de León, J. N.; Picquart, M.; Massin, L.; Vrinat, M.; de los Reyes, J. A. Hydrodesulfurization of sulfur refractory compounds: Effect of gallium as an additive in $\mathrm{NiWS} / \gamma-\mathrm{Al}_{2} \mathrm{O}_{3}$ catalysts. J. Mol. Catal. Chem. 2012, 363-364, 311-321.

(26) Breysse, M.; Djega-Mariadassou, G.; Pessayre, S.; Geantet, C.; Vrinat, M.; Perot, G.; Lemaire, M. Deep desulfurization: reactions, catalysts and technological challenges. Catal. Today 2003, 84, 129-138. 
(27) Meille, V.; Schulz, E.; Lemaire, M.; Vrinat, M. Hydrodesulfurization of Alkyldibenzothiophenes over a NiMo/ $\mathrm{Al}_{2} \mathrm{O}_{3}$ Catalyst: Kinetics and Mechanism. J. Catal. 1997, 170, 29-36.

(28) Schulz, H.; Böhringer, W.; Ousmanov, F.; Waller, P. Refractory sulfur compounds in gas oils. Fuel Process. Technol. 1999, 61, 5-41.

(29) Adam, F.; Bertoncini, F.; Brodusch, N.; Durand, E.; Thiébaut, D.; Espinat, D.; Hennion, M.C. New benchmark for basic and neutral nitrogen compounds speciation in middle distillates using comprehensive two-dimensional gas chromatography. J. Chromatogr. A 2007, 1148, 55-64.

(30) Adam, F.; Bertoncini, F.; Dartiguelongue, C.; Marchand, K.; Thiébaut, D.; Hennion, M.C. Comprehensive two-dimensional gas chromatography for basic and neutral nitrogen speciation in middle distillates. Fuel 2009, 88, 938-946.

(31) Nagai, M.; Masunaga, T.; Hanaoka, N. Hydrodenitrogenation of carbazole on a molybdenum/alumina catalyst. Effects of sulfiding and sulfur compounds. Energy Fuels 1988, 2, 645-651.

(32) Rabarihoela-Rakotovao, V.; Diehl, F.; Brunet, S. Deep HDS of Diesel Fuel: Inhibiting Effect of Nitrogen Compounds on the Transformation of the Refractory 4,6Dimethyldibenzothiophene Over a NiMoP/Al ${ }_{2} \mathrm{O}_{3}$ Catalyst. Catal. Lett. 2008, 129, 50-60.

(33) Wiwel, P.; Knudsen, K.; Zeuthen, P.; Whitehurst, D. Assessing Compositional Changes of Nitrogen Compounds during Hydrotreating of Typical Diesel Range Gas Oils Using a Novel Preconcentration Technique Coupled with Gas Chromatography and Atomic Emission Detection. Ind. Eng. Chem. Res. 2000, 39, 533-540.

(34) Jokuty, P. L.; Gray, M. R. Resistant nitrogen compounds in hydrotreated gas oil from Athabasca bitumen. Energy Fuels 1991, 5, 791-795. 
(35) Sumbogo Murti, S. D.; Yang, H.; Choi, K.-H.; Korai, Y.; Mochida, I. Influences of nitrogen species on the hydrodesulfurization reactivity of a gas oil over sulfide catalysts of variable activity. Appl. Catal. Gen. 2003, 252, 331-346.

(36) Tao, X.; Zhou, Y.; Wei, Q.; Ding, S.; Zhou, W.; Liu, T.; Li, X. Inhibiting effects of nitrogen compounds on deep hydrodesulfurization of straight-run gas oil over a $\mathrm{NiW} / \mathrm{Al}_{2} \mathrm{O}_{3}$ catalyst. Fuel 2017, 188, 401-407.

(37) Rana, M. S.; Al-Barood, A.; Brouresli, R.; Al-Hendi, A. W.; Mustafa, N. Effect of organic nitrogen compounds on deep hydrodesulfurization of middle distillate. Fuel Process. Technol. 2018, 177, 170-178. 